\title{
Oligomeric Compatibilizers for Control of phase Separation in Conjugated Polymer Blend Films
}

\author{
Joanna E. Slota, ${ }^{\dagger}$ Einat Elmalem, ${ }^{\ddagger}$ Guoli Tu, ${ }^{\ddagger}, \S$ Benjamin Watts, ${ }^{\perp}$ Junfeng Fang, ${ }^{\ddagger}, \|$ \\ Philipp M. Oberhumer, ${ }^{\circ}$ Richard H. Friend, ${ }^{\circ}$ and Wilhelm T. S. Huck ${ }^{*}, \nabla>$ \\ ${ }^{\dagger}$ Nanoscience Centre, University of Cambridge, $11 \mathrm{JJ}$ Thompson Avenue, Cambridge, CB3 0FF, U.K. \\ ${ }^{\ddagger}$ Melville Laboratory for Polymer Synthesis, University of Cambridge, Lensfield Road, Cambridge, CB2 1EW, U.K. \\ ${ }^{\S}$ Wuhan National Laboratory for Optoelectronics, Huazhong University of Science and Technology, 430074 Wuhan, P.R. China \\ ${ }^{\perp}$ Swiss Light Source, Paul Scherrer Institut, Villigen 5232, Switzerland \\ "Ningbo Institute of Materials Technology and Engineering, Chinese Academy of Sciences, Ningbo, 315211 Zhejiang, P.R. China \\ ODepartment of Physics, Cavendish Laboratory, University of Cambridge, JJ Thompson Avenue, Cambridge, CB3 0HE, U.K.

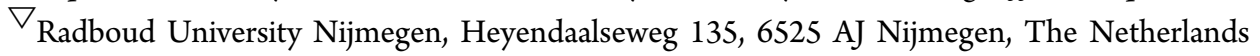

\section{Supporting Information}

ABSTRACT: Control over phase separation and morphology is critical to optimal function in polymer optoelectronic devices. Here, two fully conjugated oligomeric compatibilizers are introduced, and their effect on the phase separation of blends of poly $\left(9,9^{\prime}\right.$-dioctylfluorene-co-benzothiadiazole) (F8BT) with poly $\left(9,9^{\prime}\right.$-dioctylfluorene-co-bis- $N, N^{\prime}$ (4,butylphenyl)bis- $N, N^{\prime}$-phenyl-1,4-phenylenediamine) (PFB) are reported. AFM and STXM analysis demonstrate that the addition of compatibilizer altered the size and relative composition of phaseseparated domains formed during spin-casting. Small structural differences between the two compatibilizers brought about significantly

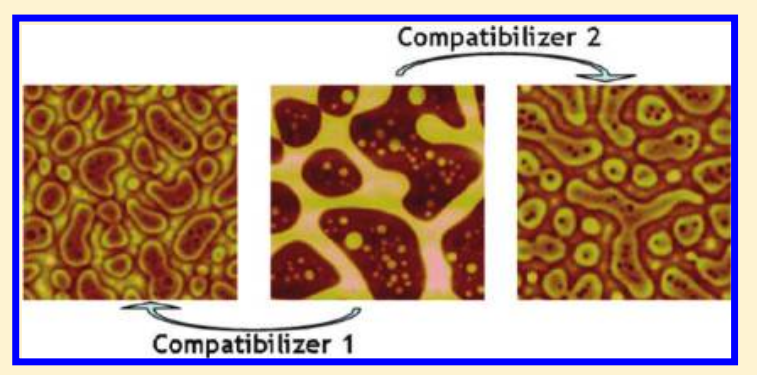
different morphological changes to the blends, suggesting that further development of compatibilizer structure could enable enhanced control toward desired blend film morphologies.

\section{INTRODUCTION}

The active layers of polymer optoelectonic devices are formed from blends of conjugated donor and acceptor polymers. Optimum performance requires, among many other parameters, control over the phase separated morphologies formed. Specifically, optimized bulk heterojunction solar cells, ${ }^{1}$ require phase separation on a scale comparable to the exciton diffusion length $(10-20 \mathrm{~nm})$ for charge separation, as well as percolation pathways to each electrode to allow uninhibited charge transport. These specifications cannot easily be controlled during facile device fabrication processes, such as spin-coating.

To enhance the effectiveness of new materials, while maintaining simplicity of production, several strategies have been employed in attempts to control the morphology in functional polymer blends. ${ }^{2-4}$ Careful regulation of the solvent evaporation rate, ${ }^{5}$ solution concentration, ${ }^{6}$ or material ratio $^{7}$ during thin film formation, as well as gentle thermal or solvent treatment of the cast films, ${ }^{8,9}$ have shown some success in manipulating morphology. Particularly promising is a strategy involving solvent additives, which are understood to alter the phase separation of blends by changing the relative solubility, hence drying times of components during casting. ${ }^{10,11}$ This method has produced some of the most efficient systems to date. ${ }^{12,13}$ These strategies rely on influencing the complicated interplay of thermodynamic and kinetic factors controlling the nonequilibrium blend morphology arising during the film formation process.

Surface-active compatibilizers are emerging as a more stable route to morphological control. Thiophene: fullerene diblock copolymers have been used as compatibilizers in poly(3hexylthiophene) (P3HT) and [6,6]-phenyl- $\mathrm{C}_{61}$-butyric acid methyl ester (PCBM) blends, lowering surface tension and suppressing the rate of phase separation. ${ }^{14-16}$ PV devices constructed from these blends showed lower efficiency but enhanced thermal stability with respect to standard devices containing no diblock copolymer. Similar work by Yang et al. also showed that small amounts of diblock copolymer altered the phase separation in the same blend, this time appearing to form larger phase domains, and enhancing the power conversion efficiency (PCE). ${ }^{17}$ Control of morphology and further enhancement of the PCE (from 3.9 to 4.4\%) of P3HT:PCBM-based devices was achieved by the addition of small amounts of a coil-rod-coil triblock copolymer surfactant, where the coil segment displayed selective miscibility

Received: July 6, 2011

Revised: January 11, 2012

Published: January 27, 2012 


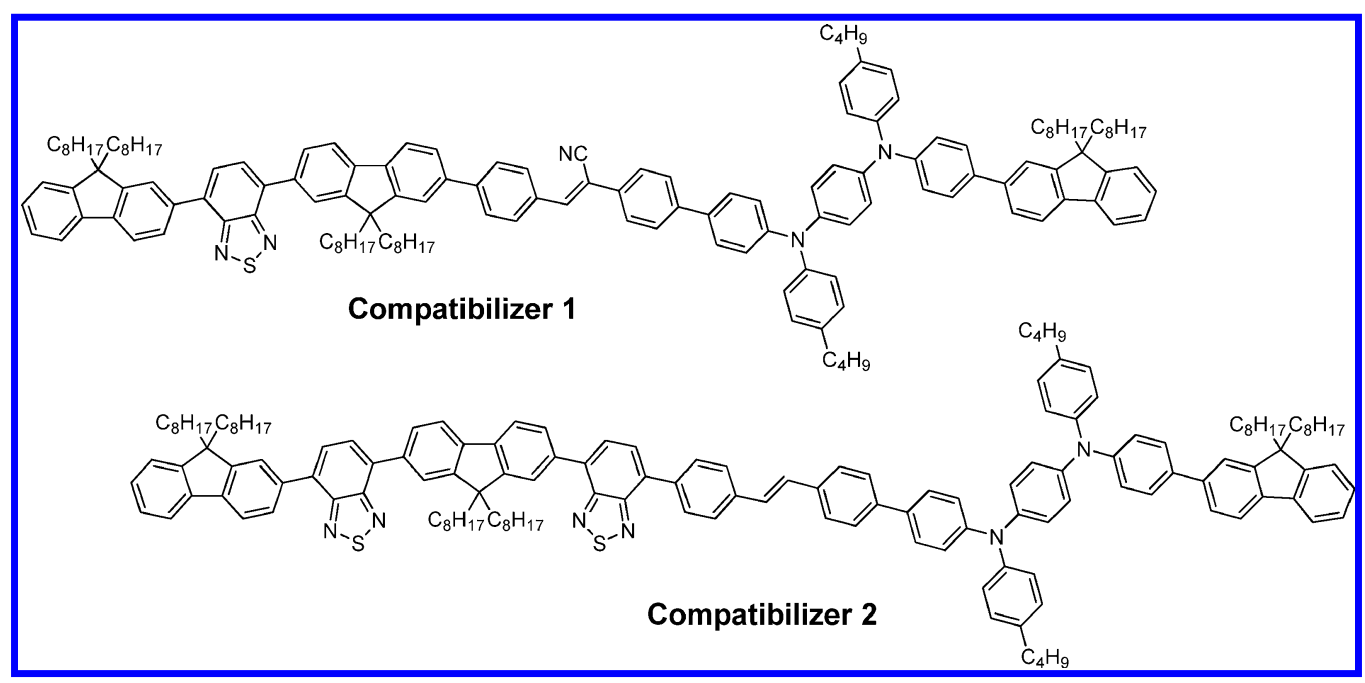

Figure 1. Chemical structures of compatibilizer 1 and compatibilizer 2; 1 has a nitrile linker unit, and 2 has a longer F8BT block: an extra benzothiadiazole (BT) unit.

in the PCBM domain. ${ }^{18}$ Suppressed phase separation and improved device efficiency has also been achieved by the addition of diblock copolymer to polymer-perylene bisimide devices. ${ }^{19}$ Effective compatibilizers with alternative architectures (branched chain polymers, or bifunctional oligomers) have also been demonstrated. ${ }^{20,21}$ Detailed morphological characterization of many of these systems, however, has generally been limited due to the small scale of phase separation.

Here we set out to investigate the morphological impact of low molecular weight oligomeric compatibilizers in a blend of two conjugated polymers. The classical compatibilizer is a diblock copolymer with blocks identical or miscible with the blend components. Although we expect that increased chain length would enhance the effect of the compatibilizer, ${ }^{22}$ this work will demonstrate that low molecular weight compatibilizers can also change interfacial properties and direct morphology. Furthermore, shorter blocks are synthetically more accessible and reduce the likelihood of forming micelles away from the surface, ${ }^{23}$ a morphology which would form disconnected phases and charge traps in polymer photovoltaic (PV) devices. The compatibilizers presented here are fully conjugated, which ameliorates the concern that the high amount of nonconjugated units inherent to other reported diblock copolymer compatibilizers may disrupt charge transport. ${ }^{17}$

Two oligomeric compatibilizers, $\mathbf{1}$ and $\mathbf{2}$, resembling the repeat units of the conjugated homopolymers used (Figure 1), were synthesized via a procedure based on successive SuzukiMiyaura cross-coupling reactions (full details in Supporting Information) and investigated for their effect on a 1:1 (by weight) blend of poly(9,9'-dioctylfluorene-co-benzo-thiadiazole) (F8BT) with poly(9,9'-dioctylfluorene-co-bis- $N, N^{\prime}$-(4butylphenyl)-bis- $N, N^{\prime}$-phenyl-1,4-phenylene-diamine) (PFB). Although the PV characteristics of this blend are modest, the system has been extensively studied as a model system for investigations into the relationship between morphology and device performance. $^{24-27}$ The two oligomers have different molecular weights and due to the different synthetic routes a slightly different linker unit; we are interested in observing differences in the phase separation as a result of differences in structure of the oligomer as this will guide further research in this area. Since the concentration of oligomers is expected to have an impact on morphology, ${ }^{28}$ blends including varying amounts of each compatibilizer were examined: [F8BT: PFB: compatibilizer] weight ratio $\left(50: 50: C_{x}\right)$, where $C_{x}=0,1.25,2.5$, $5,20,40$, or $60(x=1$ or 2$)$. Films were annealed at $120^{\circ} \mathrm{C}$ for $60 \mathrm{~min}$ to allow the full morphological modifications effected by the compatibilizer to develop. ${ }^{17}$ The resulting morphologies were characterized using tapping mode atomic force microscopy (AFM) and scanning transmission X-ray microscopy (STXM).

\section{EXPERIMENTAL SECTION}

Materials. PFB and F8BT homopolymers were supplied by Cambridge Display Technology Ltd. with molecular weights $\left(M_{\mathrm{n}}\right)$ of $60 \mathrm{~kg} \mathrm{~mol}^{-1}$ and $100 \mathrm{~kg} \mathrm{~mol}^{-1}$, and PDIs of 2.8 and 2.08, respectively. Full experimental details for the synthesis of compatibilizer molecules $\mathbf{1}$ and $\mathbf{2}$ are presented in the Supporting Information.

Preparation of Polymer Blends. $m$-Xylene solutions of each material were prepared at a concentration of $15 \mathrm{mg} \mathrm{mL}^{-1}$; blends were formed by combining an equal ratio of PFB and F8BT solutions, with varying amounts of either compatibilizer solution. These blends were spun at $2000 \mathrm{rpm}$ at room temperature onto glass substrates, which had been pretreated with oxygen plasma and coated with PEDOT:PSS. Chloroform blends were prepared by combining a 1:1 weight ratio of F8BT with PFB at a total concentration of $8 \mathrm{mg} \mathrm{mL}^{-1}$. Chloroform solutions of both compatibilizer were also prepared at a concentration of $8 \mathrm{mg} \mathrm{mL}^{-1}$ and combined with the mixed polymer solution in varying proportions. The resulting blends were spin-coated at $3000 \mathrm{rpm}$ at room temperature onto glass or ITO/glass substrates, which had been pretreated with oxygen plasma and coated with PEDOT:PSS.

Morphology Characterization. Surface morphology and film thickness was measured with tapping mode AFM (Veeco 3100 Dimension AFM, using Nanoscope VI and WSxM programmes). STXM measurements were performed at the PolLux beamline of the Swiss Light Source, Paul Scherrer Institut, Villigen, Switzerland. ${ }^{29,30}$ Sample films were floated-off the PEDOT:PSS covered, glass substrates via deionized water and mounted on copper TEM grids. Monochromated X-rays were focused onto each sample using a Fresnel zone plate to afford $\leq 50 \mathrm{~nm}$ lateral resolution. Using distinctions between the Near Edge X-ray Absorption Fine Structure (NEXAFS) spectra of F8BT and PFB (PFB displays a sharper, more intense $1 \mathrm{~s} \rightarrow \pi^{*}$ transition, with a higher onset than for F8BT; see Supporting Information), the relative composition of the two polymers was determined, following the procedure in [27]. The $5 \times 5 \mu \mathrm{m} 2 \mathrm{D} \mathrm{X}$ - 
ray absorption images were collected in transmission mode at 284.7 and $285.1 \mathrm{eV}$ (where differences in F8BT and PFB absorption are most pronounced) as well as 280 and $320 \mathrm{eV}$ (where absorption is chemically indistinct, allowing calibration for absolute film thickness); these data were fitted to thickness-calibrated spectra of pristine films, producing a measure of the relative thickness of each polymer. Linescans were also recorded across each image, where the full NEXAFS spectra were collected (147 points between 275 and $355 \mathrm{eV}$ with $0.1 \mathrm{eV}$ resolution between 283 and $290 \mathrm{eV}$ ) and fitted (by leastsquares) to a sum of pristine spectra. It should be noted that we were unable to include information with regard to the location of the compatibilizer molecules within the blend, because the NEXAFS spectrum observed for each compatibilizer approximated a linear combination of the F8BT and PFB spectra, which could not be separately resolved. ${ }^{31}$

\section{RESULTS AND DISCUSSION}

Xylene Blends. Previous studies have elucidated the phase separation regime for bulk heterojunction blends of F8BT and PFB spun from high boiling point solvents such as xylene; the binary film morphology measured here (Figure 2, top row) is

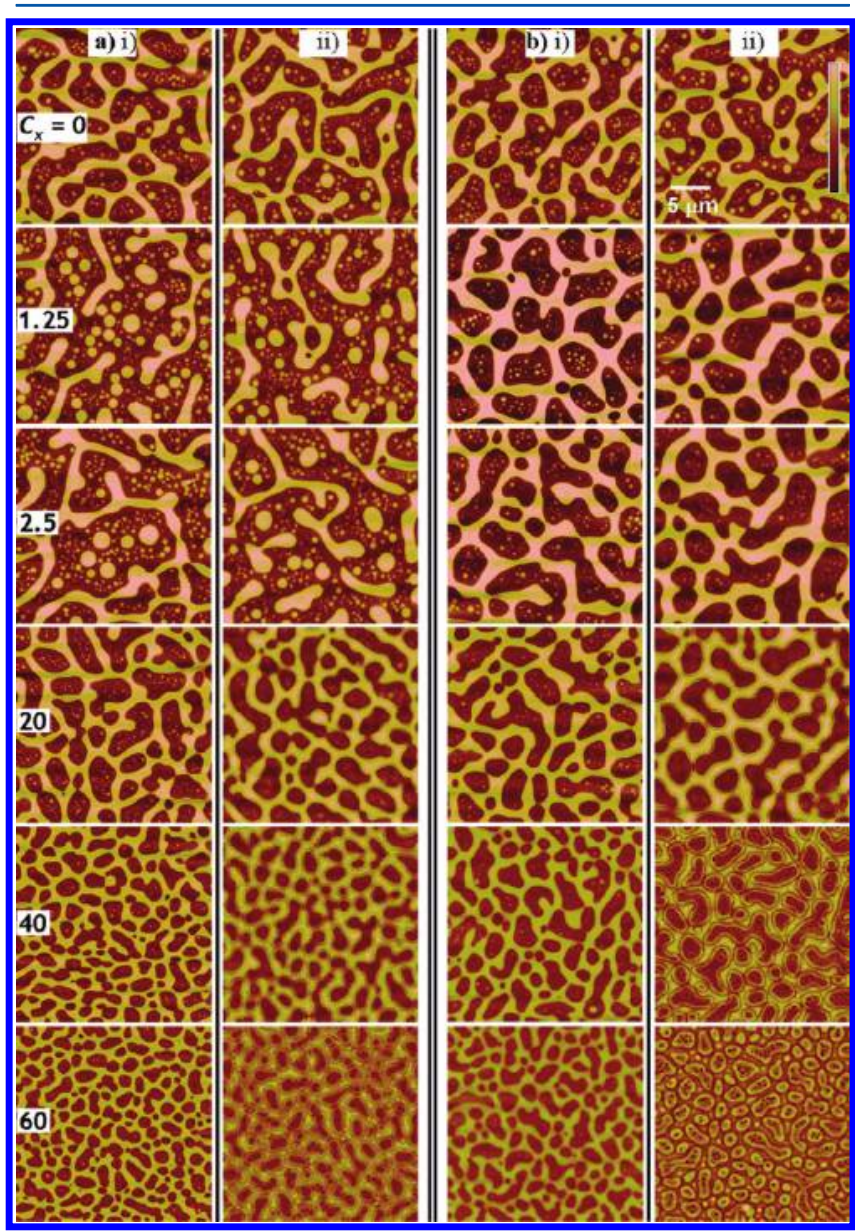

Figure 2. AFM height micrographs of (a) [F8BT:PFB:1] and (b) [F8BT:PFB:2] blends, weight ratio $\left(50: 50: C_{x}\right)$, (i) after spin-coating from xylene and (ii) after annealing at $120^{\circ} \mathrm{C}$ for $60 \mathrm{~min}$. The relative weight of compatibilizer included in each blend is indicated on the left. (The height scale represents $60 \mathrm{~nm}$.)

consistent with previous examples. ${ }^{32-36}$ The films display vertically depressed PFB-rich areas interspersed within a raised F8BT-rich matrix (the F8BT-rich zones having an under-layer, and partial capping-layer of $\mathrm{PFB}$, and the PFB-rich zones including smaller F8BT-rich spots), a morphology driven by the immiscibility of the polymers, and the lower solubility of F8BT in xylene. ${ }^{24-27}$

The microscale phase separation in these films allowed morphological changes to be clearly characterized as an increasing proportion of compatibilizer was added, and as the films evolved under thermal annealing. The AFM topography micrographs presented in Figure 2 qualitatively show that significant morphological change was induced by the inclusion of even small amounts of compatibilizer, and that small structural differences between compatibilizers 1 and $\mathbf{2}$ (an extra benzothiadiazole unit on the F8BT block of 2 , and a nitrile linker group on 1; Figure 1) were nonetheless sufficient to alter the blend interaction during film formation to result in differing morphologies.

The full AFM data set was summarized in terms of morphological parameters most relevant to polymer PV device performance: estimates of the amount of interface between components, size and frequency of phases and surface roughness (Figure 3).

A general decrease in surface roughness and reduction of the size of PFB-rich phases was observed upon adding large amounts of either compatibilizer $\left(C_{x} \geq 20\right)$. Reduced size and increased frequency of PFB-rich phases led to an increase in the interface between microphases in some compatibilizer blends. The largest amount of added compatibilizer in the blends $\left(C_{1}\right.$ or $C_{2}=60$ ) resulted in a $\sim 34 \%$ and $\sim 18 \%$ increase in the estimated interface between microphases, respectively, compared to blends containing no compatibilizer. Notably, in addition to this general trend toward finer phase separation and larger interfacial lengths, very low amounts of compatibilizer $\left(C_{x}=1.25,2.5\right)$ had a striking impact, often contrary to this trend. For example, addition of $C_{1}=1.25$ led to a $424 \%$ increase in the size of PFB-rich phases; effectively the interaction of the compatibilizer in the blend altered the phase separation during film formation so as to prevent the F8BT-rich zones from forming a connecting matrix in the normal manner. This morphology also displayed a $3 \%$ increase in roughness, and an $18 \%$ increase in the estimated microphase interface. The interaction in the blend containing $C_{2}=1.25 \mathrm{did}$ not act in the same manner, but led to a $54 \%$ increase in roughness, raising the F8BT-rich matrix higher above the PFBrich zones than seen for the binary blend; this morphology displayed a $19 \%$ drop in the estimated microphase interface, compared to the binary blend. These results indicate that the phase separation is sensitive to the molecular structure of the oligomeric compatibilizer.

Further qualitative changes were observed upon annealing (Figure 2, parts a(ii) and $\mathrm{b}(\mathrm{ii})$ ), such as the appearance of trenches encircling the depressed phases by $\sim 0.3-0.4 \mu \mathrm{m}$. For blends including $C_{1}=40$ or 60 , these trenches were $2 \pm 0.5 \mathrm{~nm}$ deep, and for blends including $C_{2}=20$ and 40, the trenches were $4 \pm 2 \mathrm{~nm}$ and $9 \pm 1.5 \mathrm{~nm}$ deep, respectively. A change in relative thickness between the PFB-rich phases and the F8TBTrich matrix was also seen (leading to an unusual morphology of raised regions within a lowered matrix for the $C_{2}=60$ blend after $60 \mathrm{~min}$ at $120^{\circ} \mathrm{C}$ (Figure 2, bottom right). These unusual morphologies have not before been reported for F8BT: PFB blends, ${ }^{24}$ or related F8BT:TFB blends. ${ }^{37}$

The chemical composition within the blends was investigated using STXM, ${ }^{27,32}$ which produced 2D composition and thickness maps. Linescans corresponding to each image were also measured, which gave a more accurate analysis of the 


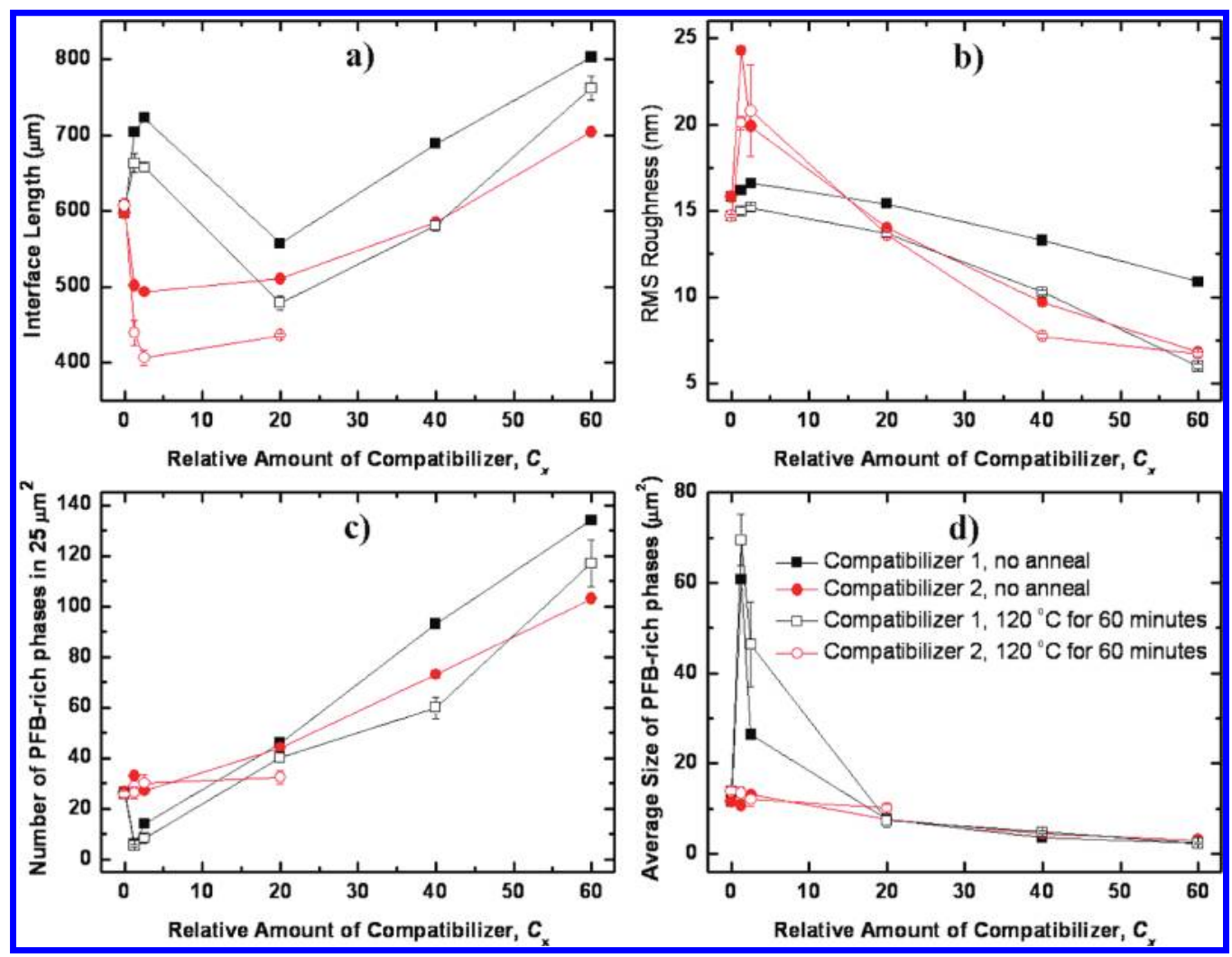

Figure 3. Analysis of AFM height data for [F8BT: PFB: compatibilizer] polymer blends, weight ratio (50:50: $C_{x}$ ), spun from xylene: (a) Amount of interface between PFB and F8BT rich phases, measured as a length in a 2D, $625 \mu \mathrm{m}^{2}$ slice. (b) Rms roughness of the film surfaces. (c) Number of PFB-rich phases in $625 \mu \mathrm{m}^{2}$ of film. (d) Average size of PFB-rich phases. Each data point represents average values over three $625 \mu \mathrm{m}^{2}$ AFM micrographs.

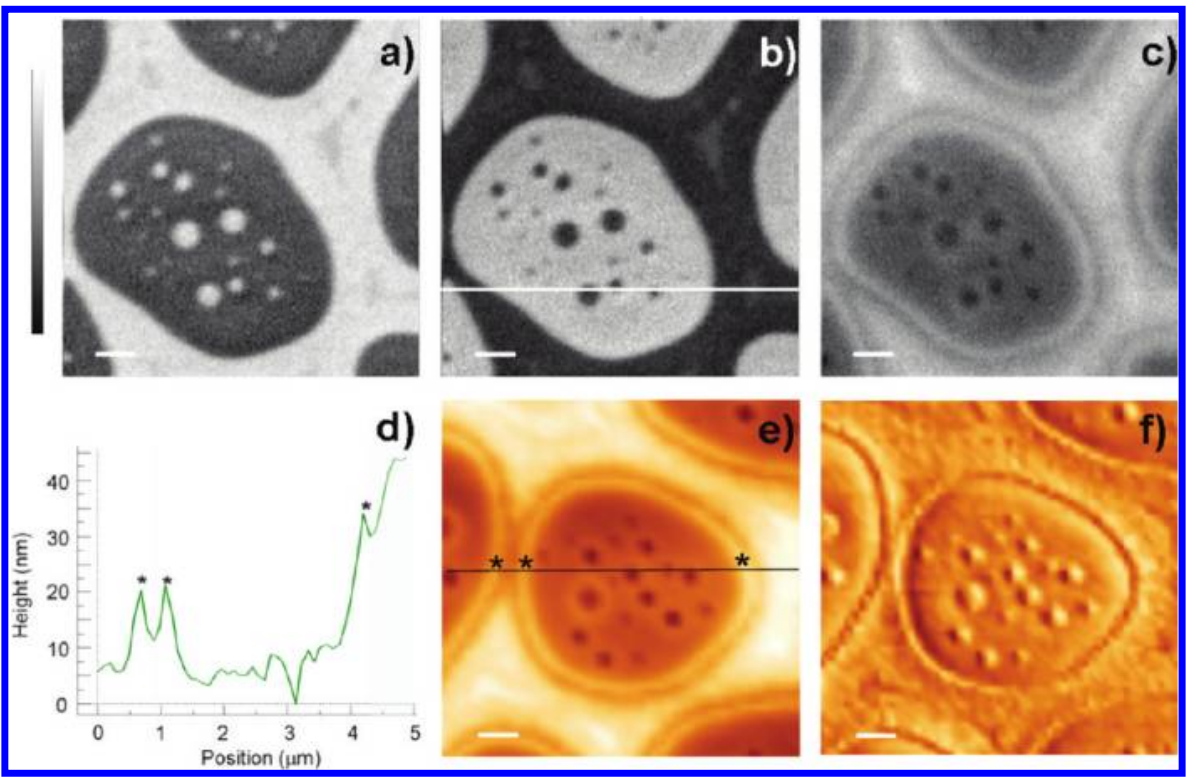

Figure 4. Characterization of [F8BT: PFB: 2] $\left(C_{2}=20\right)$ blends spun from xylene, after annealing at $120{ }^{\circ} \mathrm{C}$ for $60 \mathrm{~min}$. STXM: (a) F8BT composition, (b) PFB composition and (c) total film thickness (height scale $68 \mathrm{~nm}$ ). AFM: (d) height profile, (e) height micrograph, and (f) phase micrograph. (The black line in part e indicates the position of linescan d; the white line in part b indicates the position of the corresponding STXM linescan shown in Figure 6c(ii).) Scale bars indicate $500 \mathrm{~nm}$.

composition and thickness within the distinct phases. Comparison of the STXM 2D composition and thickness maps with the AFM micrographs (the data for $C_{2}=20$ is shown in Figure 4) revealed that the observed trenches outline the edge of the PFB-rich phases, that is, the edges of the PFB-rich zones became raised (indicated with stars in Figures 4, parts d and e). Examination of the STXM linescan thickness and composition profiles (Figures 5 and 6), more fully demonstrated that upon addition of large relative amounts of compatibilizer $\left(C_{x} \geq 20\right.$, and after annealing), the PFB-rich 


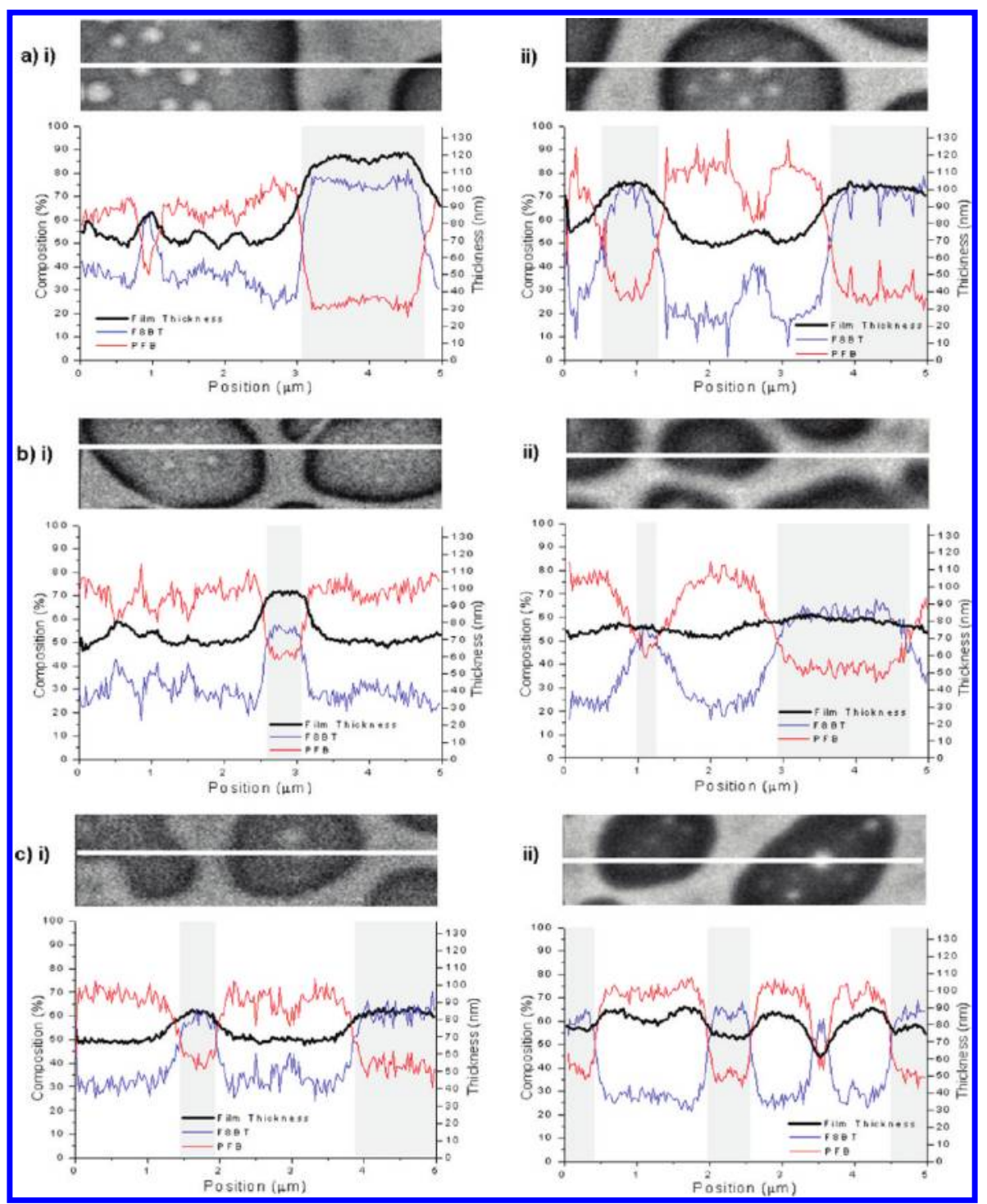

Figure 5. Composition and total film thickness profiles calculated from STXM linescans for films composed of (a) [F8BT: PFB] blends, (b) [F8BT: PFB: 1] $C_{1}=60$, and (c) [F8BT: PFB: 2] $C_{2}=60$, (i) after spin coating from xylene and (ii) after annealing at $120^{\circ} \mathrm{C}$ for $60 \mathrm{~min}$. (As a guide to the eye, areas corresponding to the F8BT-rich matrix phase are shaded.) Corresponding regions of the $2 \mathrm{D} \mathrm{X}$-ray absorption scans at $285 \mathrm{eV}$ are also shown (since PFB absorbs more strongly at this wavelength, PFB-rich areas appear darker in color); white lines indicate the positions of linescans.

phases became thicker at the edges, wetting the sides of the F8BT-rich matrix. Analysis of the STXM linescans also revealed that the apparent change in relative thickness of phases on annealing (in films containing compatibilizer), was due to thinning of the F8BT-rich phase, while the average thickness of the PFB-rich phase remained relatively unchanged (Figure $7 \mathrm{~b}$ ). For large amounts of added compatibilizer 2, the raised edges of the PFB-rich domains protruded beyond the F8BT-rich matrix, effectively reversing the regular morphology for F8BT: PFB blends of this type. These results suggest that the presence of compatibilizer may alter interactions with the solvent during film formation. Thinning of the F8BT-rich phase could be caused by an increased solubility of F8BT in xylene due to the interaction of the compatibilizer. An increased solubility would cause the F8BT phase to precipitate out of solution at a later stage of the spin-casting process, when more solvent had evaporated, hence resulting in a thinner film.

In photovoltaic devices based on this particular polymer system, photocurrent is usually generated within the intermixed microdomains, and not preferentially at the domain bounda- ries. $^{38}$ Therefore, we also analyzed compositional changes taking place within the microscale domains (data presented in Figures 5 and 6 are summarized in Figure 7). In the case of the binary F8BT: PFB blend with no added compatibilizer and no thermal annealing, the F8BT-rich phase shows slightly higher purity (76\% F8BT) than the PFB-rich phase (66\% PFB) (Figure $5 \mathrm{a}(\mathrm{i}))$; although this contrast is not as striking as seen in previous studies, perhaps due to slightly different solubilities in $m$-xylene rather than $p$-xylene $\left.{ }^{27}\right)$. After annealing at $120^{\circ} \mathrm{C}$ for $60 \mathrm{~min}$, the PFB-rich domain of the binary blend became the most pure (Figure $5 \mathrm{a}(\mathrm{ii})$ ); $80 \%$ PFB compared to $70 \%$ F8BT). This may be due to the movement of smaller F8BT domains within the PFB-rich region toward larger F8BT-rich discrete inclusions or continuous matrix, through Ostwald ripening, as is thought to occur when the films undergo solvent annealing. ${ }^{32}$ For the annealed samples including compatibilizer, PFB is also generally the purest phase ( $66-78 \%$ PFB). This PFB purity decreases rapidly for low addition of compatibilizer $\left(C_{x} \leq 20\right)$, but increases steadily with further addition of either compatibilizer $\left(C_{x}>20\right)$ : Upon addition of $C_{2}=2.5$ to the 

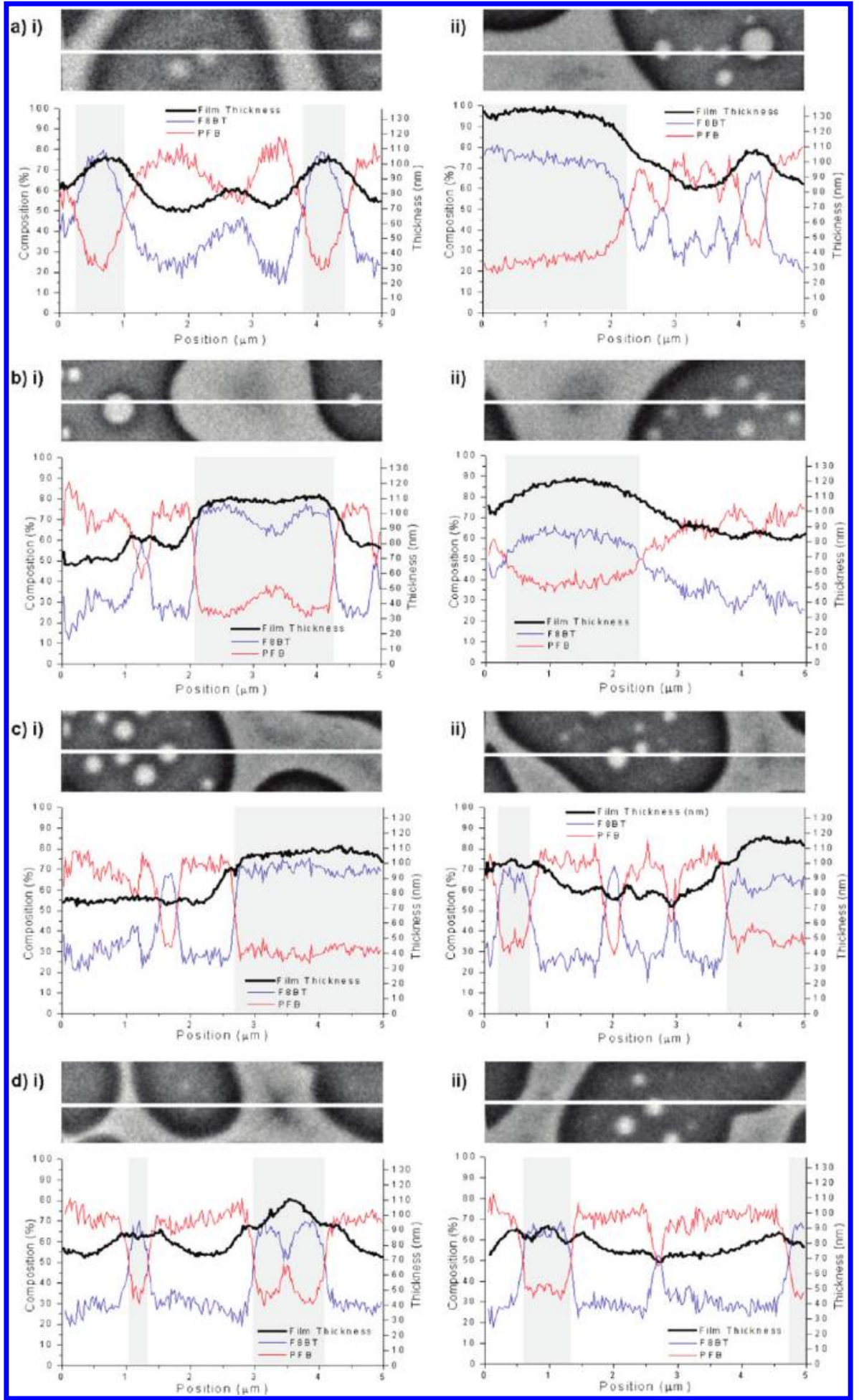

Figure 6. Composition and total film thickness profiles calculated from STXM linescans for films composed of (i) [F8BT: PFB: 1] or (ii) [F8BT: PFB: 2], weight ratio (50:50: $C_{x}$ ), spun from xylene, where $C_{x}$ is (a) 1.25, (b) 2.5, (c) 20, and (d) 40; all samples were annealed at $120^{\circ} \mathrm{C}$ for 60 min. (As a guide to the eye, areas corresponding to the F8BT-rich matrix phase are shaded.) Corresponding regions of the $2 \mathrm{D} \mathrm{X}$-ray absorption scans at $285 \mathrm{eV}$ are also shown (since PFB absorbs more strongly at this wavelength, PFB-rich areas appear darker in color); white lines indicate the positions of linescans.

binary blend, the PFB-phase purity drops by $14 \%$ to $66 \%$, but in the presence of $C_{2}=60$ the purity is raised to $74 \% \mathrm{PFB}$. The steady increase in PFB purity for $C_{x}>20$ (Figure 7a) mirrors the steady reduction in domain size observed in the AFM data (Figure 3).
The F8BT-rich phases in these samples become much less pure when high amounts of compatibilizer are included, to a minimum of $55 \%$ F8BT in the case of $C_{1}=40$. Since the purity of F8BT-rich phases seems to decrease more than the purity of PFB-rich phases increases for high amounts of added compatibilizer (Figure 7), we expect that either the interaction 


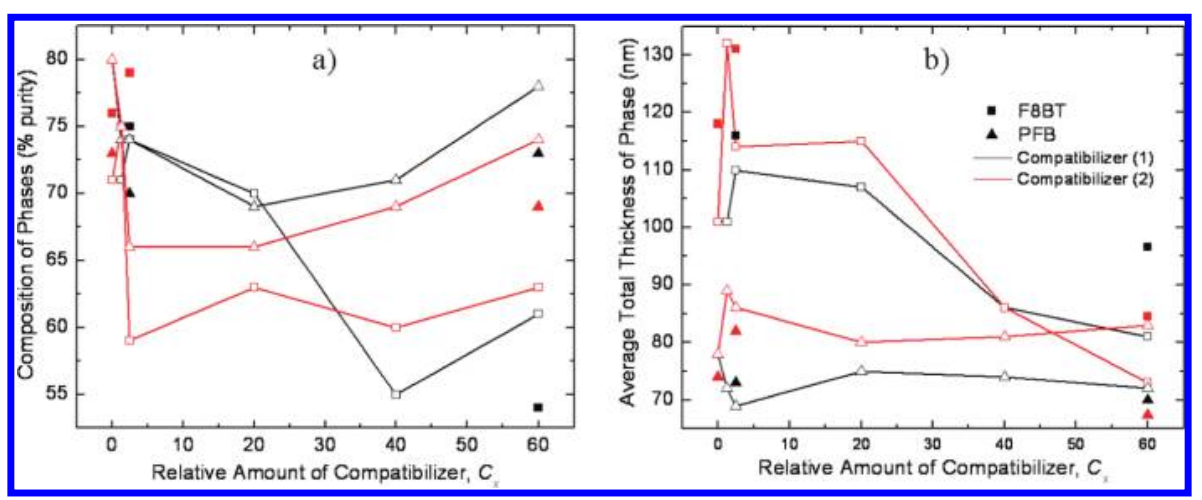

Figure 7. Summary of STXM data for [F8BT: PFB: compatibilizer] polymer blends, weight ratio $\left(50: 50: C_{x}\right)$, spun from xylene: (a) composition and (b) thickness of F8BT- and PFB-rich phases. Squares represent F8BT phases, triangles represent PFB phases; black or red indicates that compatibilizer 1 or compatibilizer $\mathbf{2}$ was used, respectively; filled squares/rectangles indicate no annealing, whereas open squares/rectangles indicate that the samples were annealed at $120{ }^{\circ} \mathrm{C}$ for $60 \mathrm{~min}$. Lines are included as a guide to the eye.

of the compatibilizer enhances the miscibility of PFB in F8BT, or that the compatibilizer itself is located preferentially in the F8BT-rich phase.

\section{CONCLUSIONS}

Two fully conjugated oligomeric compatibilizers were synthesized and investigated for their efficacy as morphology directors within a functional blend of the corresponding homopolymers: F8BT and PFB. A combination of AFM and STXM analysis revealed that the effects of added compatibilizer were diverse and could not easily be predicted. We can draw a number of general conclusions from our experiments: (i) small amounts of $\mathrm{C}_{1}$ resulted in large increases in interfacial area as the F8BT phase no longer formed a connected matrix; (ii) large amounts of either compatibilizer resulted in significant morphological changes in the blends spin-coated from xylene; (iii) the addition of compatibilizer influences the composition of the phases, with a general trend of lower purity with larger amounts added.

The results described here indicate that the phase separation of semiconducting polymer blends can be influenced by small molecule compatibilizers. However, the decrease in purity of the phases also strongly indicates that the compatibilizers used here are not strongly anchored at the interface and that a complex ternary system forms with increasing amounts of compatibilizer added. Future studies will study polymer blends that undergo more complete phase separation and investigate polymeric compatibilizers which will be expected to localize at the interface more strongly.

Control over blend film morphology in this manner allows the electronic performance and favorable phase separation properties of polymers to be pursued and optimized separately, thus allowing greater focus in the synthesis of new conjugated polymers for electronic device applications.

\section{ASSOCIATED CONTENT}

\section{S Supporting Information}

Experiemental section giving synthesis and characterization details, including NEXAFS spectra, and AFM and EQE data. This material is available free of charge via the Internet at http://pubs.acs.org/.

\section{AUTHOR INFORMATION}

\section{Corresponding Author}

*E-mail: wtsh2@cam.ac.uk.

\section{Notes}

The authors declare no competing financial interest.

\section{ACKNOWLEDGMENTS}

The authors would like to thank Dr Chris McNeill for making arrangements with SLS and for valued discussion, the SLS for beamtime and Cambridge Display Technology Ltd. for the supply of conjugated homopolymers used in this study. PolLux is funded by the BMBF (project no. 05KS7WE1).

\section{REFERENCES}

(1) Tang, C. W. Appl. Phys. Lett. 1986, 48, 183.

(2) Yang, X.; Loos, J. Macromolecules 2007, 40, 1353.

(3) Hoppe, H.; Sariciftci, N. S. J. Mater. Chem. 2006, 16, 45.

(4) Slota, J. E.; He, X.; Huck, W. T. S. Nano Today 2010, 5, 231.

(5) Yang, X.; van Duren, J. K. J.; Rispens, M. T.; Hummelen, J. C.; Janssen, R. A. J.; Michels, M. A. J.; Loos, J. Adv. Mater. 2004, 16, 802.

(6) Hoppe, H.; Neggemann, M.; Winder, C.; Kraut, J.; Hiesgen, R.; Hinsch, A.; Meissner, D.; Sariciftci, N. S. Adv. Funct. Mater. 2004, 14, 1005.

(7) Park, S. H.; Roy, A.; Beaupre, S.; Cho, S.; Coates, N.; Moon, J. S.; Moses, D.; Leclerc, M.; Lee, K.; Heeger, A. J. Nat. Photon. 2009, 3, 297.

(8) Reyes-Reyes, M.; Kim, K.; Dewald, J.; Lopez-Sandoval, R.; Avadhanula, A.; Curran, S.; Carroll, D. L. Org. Lett. 2005, 7, 5749.

(9) Zhao, Y.; Xie, Z.; Qu, Y.; Geng, Y.; Wang, L. Appl. Phys. Lett. 2007, 90, 043504.

(10) Peet, J.; Kim, J. Y.; Coates, N. E.; Ma, W. L.; Moses, D.; Heeger, A. J.; Bazan, G. C. Nat. Mater. 2007, 6, 497.

(11) Lee, J. K.; Ma, W. L.; Brabec, C. J.; Yuen, J.; Moon, J. S.; Kim, J. Y.; Lee, K.; Bazan, G. C.; Heeger, A. J. J. Am. Chem. Soc. 2008, 130, 3619.

(12) Liang, Y.; Feng, D.; Wu, Y.; Tsai, S.-T.; Li, G.; Ray, C.; Yu, L. J. Am. Chem. Soc. 2009, 131, 7792.

(13) Liang, Y.; Xu, Z.; Xia, J.; Tsai, S.-T.; Wu, Y.; Li, G.; Ray, C.; Yu, L. Adv. Mater. 2010, 22, E135.

(14) Lee, J. U.; Jung, J. W.; Emrick, T.; Russell, T. P.; Jo, W. H. Nanotechnology 2010, 21, 105201.

(15) Sivula, K.; Ball, Z. T.; Watanabe, N.; Frechet, J. M. J. Adv. Mater. 2006, 18, 206.

(16) Lee, J. U.; Jung, J. W.; Emrick, T.; Russell, T. P.; Jo, W. H. J. Mater. Chem. 2010, 20, 3287.

(17) Yang, C.; Lee, J. K.; Heeger, A. J.; Wudl, F. J. Mater. Chem. 2009, 19, 5416.

(18) Tsai, J.-H.; Lai, Y.-C.; Higashihara, T.; Lin, C.-J.; Ueda, M.; Chen, W.-C. Macromolecules 2010, 43, 6085.

(19) Rajaram, S.; Armstrong, P. B.; Kim, B. J.; Frechet, J. M. J. Chem. Mater. 2009, 21, 1775. 
(20) Economopoulos, S. P.; Chochos, C. L.; Gregoriou, V. G.; Kallitsis, J. K.; Barrau, S.; Hadziioannou, G. Macromolecules 2007, 40, 921.

(21) Kim, J. B.; Allen, K.; Oh, S. J.; Lee, S.; Toney, M. F.; Kim, Y. S.; Kagan, C. R.; Nuckolls, C.; Loo, Y.-L. Chem. Mater. 2010, 22, 5762.

(22) Jo, W. H.; Kim, S. H. Macromolecules 1996, 29, 7204.

(23) Noolandi, J.; Hong, K. M. Macromolecules 1982, 15, 482.

(24) Organic Photovoltaics: Materials, Device Physics and Manufacturing Technologies; Brabec, C., Scherf, U., Dyakonov, V. Wiley VCH: New York, 2008.

(25) Arias, A. C.; MacKenzie, J. D.; Stevenson, R.; Halls, J. J. M.; Inbasekaren, M.; Woo, E. P.; Richards, D.; Friend, R. H. Macromolecules 2001, 34, 6005 .

(26) Halls, J. J. M.; Arias, A. C.; MacKenzie, J. D.; Wu, W.; Inbasekaran, M.; Woo, E. P.; Friend, R. H. Adv. Mater. 2000, 12, 498. (27) McNeil, C. R.; Watts, B.; Thomsen, L.; Ade, H.; Greenham, N. C.; Dastoor, P. C. Macromolecules 2007, 40, 3263.

(28) Ni, P. H.; Zhang, M. Z.; Zhuge, L. J.; Fu, S. K. J. Polym. Sci., Part A: Polym. Chem. 2002, 40, 3734.

(29) Raabe, J.; Tzevetkov, G.; Flechsig, U.; Boge, M.; Jaggi, A.; Sarafimov, B.; Vernooij, M. G. C.; Huthwelker, T.; Ade, H.; Kilcoyne, D.; Tyliszczak, T.; Fink, R. H.; Quitmann, C. Rev. Sci. Instrum. 2008, 79, 113704.

(30) Flechsig, U.; Quitmann, C.; Raabe, J.; Booge, M.; Fink, R.; Ade, $\mathrm{H}$. The PolLux microspectroscopy beamline at the Swiss Light Source In 9th International Conference on Synchrotron Radiation Instrumentation; Choi, J. Y., Rah, S. Eds.; American Instute of Physics: Melville, NY, 2006.

(31) Analysis was aided by aXis2000 (an IDL widget available from http://unicorn.mcmaster.ca/aXis2000.html).

(32) McNeill, C. R.; Watts, B.; Thomsen, L.; Belcher, W. J.; Greenham, N. C.; Dastoor, P. C.; Ade, H. Macromolecules 2009, 42, 3347.

(33) Stevenson, R.; Arias, A. C.; Ramsdale, C.; MacKenzie, J. D.; Richards, D. Appl. Phys. Lett. 2001, 79, 2178.

(34) Chiesa, M.; Burgi, L.; Kim, J.-S.; Shikler, R.; Friend, R. H.; Sirringhaus, H. Nano Lett. 2005, 5, 559.

(35) Watts, B.; McNeill, C. R. Macromol. Rapid Commun. 2010, 31, 1706.

(36) Arias, A. C.; Corcoran, N.; Banach, M.; Friend, R. H.; MacKenzie, J. D.; Huck, W. T. S. Appl. Phys. Lett. 2002, 80, 1695.

(37) Yim, K.-H.; Zheng, Z.; Friend, R. H.; Huck, W. T. S.; Kim, J.-S. Adv. Funct. Mater. 2008, 18, 2897.

(38) Coffey, D. C.; Ginger, D. S. Nat. Mater. 2006, 5, 735. 